\title{
An Examination of Longevity of Impact of an International Practicum Experience on Teachers' Beliefs and Practices Four Years Later
}

\author{
Nancy Maynes ${ }^{1}$, John Allison ${ }^{1} \&$ Lynn Julien-Schultz ${ }^{1}$ \\ ${ }^{1}$ Schulich School of Education, Nipissing University, Canada \\ Correspondence: Nancy Maynes, Schulich School of Education, Nipissing University, 100 College Dr., North \\ Bay, Ontario, P1B 8L7, Canada. Tel: 1-705-474-3450 Ext. 4388. E-mail: nancym@nipissingu.ca
}

Received: February 28, 2012

Accepted: March 11, 2013 Online Published: March 20, 2013

doi:10.5539/ies.v6n4p154

URL: http://dx.doi.org/10.5539/ies.v6n4p154

\begin{abstract}
In March 2009, seventeen preservice teachers and their Faculty of Education supervisors spent three weeks living in rural Kenya and teaching in the schools built and supported by a well-known NGO. The impact of this experience on the preservice teachers was studied nine months after the trip. Now, over four years later, we have conducted a further phenomenological investigation with two of the original participants to examine their perception of the longevity of impact of this experience on their lives, their careers, and the personal and professional choices they make as a result of their Kenyan experience. Purposive sampling was used to illuminate the richness of individual experience and the philosophical synthesis each participant has undertaken to make strong commitments in their current choices and practices. It is evident that long-term impacts can be realized in relation to teachers' curriculum views, world views, and sense of personal empowerment from the experience of international practicum experiences in developing countries. Proposals for action by Faculties of Education are recommended.
\end{abstract}

Keywords: international practicum, phenomenology, longevity of impact

\section{Introduction}

As part of a pre-service teacher education program in a small northern Canadian university, students have the option to participate in an alternative practicum experience. They may choose to engage in practicum for up to three weeks in developing settings in Kenya or other international contexts. In 2009, seventeen pre-service teachers chose the option to teach in rural Kenyan schools under the auspices of a well-known NGO. Following the practicum experience in Kenya, researchers conducted structured interviews with participants and examined their perceptions of the impact of these experiences on their beliefs and practices, including the personal and career choices of the participants. From this research (Maynes, Allison, \& Julien-Schultz, 2012), we developed a three-part framework to report our analysis of the participants' reflections and observations about their learning in this international context. This framework included analysis of the participants' curriculum views, world views, and sense of personal empowerment. Each of these categories was expanded further to identify sub-components of their reflections (Table 1).

Table 1. Framework for analyzing previous research about impacts of an international practica

\begin{tabular}{lll}
\hline CURRICULUM VIEW & WORLD VIEW & PERSONAL EMPOWERMENT \\
\hline $\begin{array}{l}\text { Commitment to child-centered } \\
\text { pedagogy }\end{array}$ & $\begin{array}{l}\text { Commitment to planetary } \\
\text { sustainability }\end{array}$ & Belief in the power of individuals \\
$\begin{array}{l}\text { Awareness of individual } \\
\text { differences in children }\end{array}$ & $\begin{array}{l}\text { Viewing the world as an } \\
\text { independent system } \\
\text { Curriculum choices }\end{array}$ & $\begin{array}{l}\text { Commitment to basic human } \\
\text { rights }\end{array}$ \\
$\begin{array}{l}\text { Teaching strategies that celebrate } \\
\text { children's uniqueness }\end{array}$ & $\begin{array}{l}\text { Valuing cultural diversity and } \\
\text { intercultural understanding }\end{array}$ & \\
\hline
\end{tabular}


At this juncture, we were interested in revisiting some of the participants in the original group of 17 pre-service teachers to consider the long-term impact of their experience. It has been over 4 years since the pre-service teachers taught in Kenya. We were interested in their perception of how they feel they have changed, and what changes appear to have been sustained or have evolved over the past four years, including what beliefs and practices they attribute directly to their teaching in Kenya. Specifically, we chose to reexamine their curriculum views, their world views, and their expressions of personal empowerment since each of these were dominant themes in the earlier research, as well as to examine any emerging themes that seemed to be evident after some time had elapsed since the experience in Kenya.

\section{Literature Review}

Phenomenology was used as our research methodology. In our literature review we have examined several previous phenomenological approaches that relate to international experiences as an aspect contributing to professional growth. It is the study of life experiences and how each person interprets those experiences (Cohen, Kahn, \& Steeves, 2000; Creswell, 2002; Husserl, 1970; Moustakas, 1994; Van Manen, 1990). In examining the experiences of teacher-candidates, as with all research subjects, in the frenetic pace of the pre-service year and the practicums associated with it, it is easy to overlook the unique nature of every teacher-candidates' lived experience (Cohen et al., 2000). The meanings that teacher-candidates create can only be revealed through dialogue and discussion - they cannot be taken as understood by teaching faculty in pre-service programs (Cohen et al., 2000). Cohen, her colleagues and Creswell give us a good idea of the philosophical antecedents of phenomenological research (Cohen et al., 2000; Creswell, 2002). In reviewing the literature we focused on examining research which addressed the following questions; 1. Did the authors use a phenomenological methodology when conducting their research? 2. Did the research address questions of teacher education and practicums? 3. Did the research tackle issues in international education, and lastly, 4. Did the research address the long-term impact of international field experiences?

Firstly, in addressing question one, that authors looked only at works using the phenomenological methodology. In moving to the second question, the experiences of pre-service teachers and serving teachers have been well examined through the phenomenological lens (Armstrong, 2009; Bernard, 2005; Dall'Alba, 2010; Putney, 2011; Swisher, 2011; Van Benschoten \& Albany, 2008). Phenomenological research is becoming well entrenched in the field of education, as a methodology for examining the impact of experiences on practices. In looking at the broad scope of the research, Putney's examination of the responses of teachers to government policy in education clearly indicates the lively nature of this approach (Putney, 2011). Others also looked at issues like supply teaching (Betts, 2006). In tackling the question of practice teaching directly, a variety of different approaches were taken. Bowen focuses on learning through student co-teaching (Bowen, Roth, Gupta, Sefton, Stanley, Dalton, library, Saklak, Stanley, \& Zimmerman, 2002). Student-teachers who worked in groups of two could work together and solve issues during their practicums.(Bowen et al., 2002). Van Manen, in his early piece, reflects on the importance of the practical knowledge of the classroom (Van Manen, 1995). More recent articles have focused on teachers' will to learn and practical knowledge (Grushka, McLeod, \& Reynolds, 2005; Van Eekelen, Vermunt, \& Boshuizen, 2006; Van Manen, 2008). Giles focuses on the lived experience in the teacher-student relationship in his work in teacher preparation programs in New Zealand (Giles, 2008). Kennedy writes on the possibilities of a "virtual school" and the experiences of teacher candidates in a practicum associated with this type of school (Kennedy, 2010). Some pre-service teachers learned from their associate teachers how to address issues of diversity in their practicums as Guo illustrates (Guo, Arthur, \& Lund, 2009). However, little phenomenological research related to the context of international education experiences years after the experience.

Although a phenomenological approach has been used to look at international issues in education, much of the research has focused on international teaching assistants coming to industrialized countries and the experiences they have undergone in making this transition. In these analyses, the focus is on the adaptation to teaching in a foreign environment followed by a nuanced effort to derive meaning from the new cultural environment. The question of culture shock is also very important in this type of analysis (Ross \& Krider, 1992). The challenge of going through a variety of stages of adaptation also plays a role in the adaptation to the new culture (Ross \& Krider, 1992). Transcendental phenomenological approaches were used to examine the reactions of Chinese international teaching assistants as they undertook duties in a mid-sized university in the United States Mid-West (Larocco, 2011). Larocco focused her discussions on a key question; "What is the essence of the factors that affect the development of intercultural competence from the perspectives of ITAs (Larocco, 2011)?" While this focus is reflective of our research as well, again the aspect of longevity of impact on teachers' beliefs and practices was absent in this body of research. 
However, several authors have examined the longevity of impact of international experiences on other professionals. Some authors, in their studies of exchange and international teaching, took a phenomenological approach and examined the results of teaching abroad later in teachers' careers and professional experiences abroad generally (Ferguson, 2011; Orndorff, 1999; Rapoport, 2008). In their article on nursing, Melby, Dodgson and Tarrent looked at the life journeys of eight nurses over a period of two years using a phenomenological analysis of their experiences in East-Asia (Japan, Hong Kong and Thailand) (Melby, Dodgson, \& Tarrant, 2008).

The phenomenological approach has been less used to look at the impact of international teacher practicums on long-term current professional actions, hence the necessity of this study. Baxter, in his recent thesis, looks at the long-term impacts of international practicums, five and six years following their completion, using narrative inquiry (Baxter, 2012). In their study Maha and Linder examine the question, "What was the meaning, in relation to diversity, of a semester-long study abroad (SA) experience to Brussels, Belgium for male teacher education (TE) students" (McGaha \& Linder, 2012)? These authors conclude in their study that study abroad experiences of student-teachers can extend beyond the classroom to service activities and tourism and do not have to be limited to student teaching or classroom practicum internships (McGaha \& Linder, 2012). A phenomenological approach (hermeneutics) was taken by other authors to look at consonance and dissonance in international long study practicums in England (Brindley, Quinn, \& Morton, 2009) but did not address the disparity in culture that was evident in teaching practica in a developing country. In a different approach, another group of authors used a phenomenological approach to examine the spiritual dynamics of student teachers on an international practicum (Firmin, Firmin, \& MacKay, 2009). Their main research focus was "to address their perceptions of the role that spiritual dynamics played in their respective overseas student teaching experiences"(Firmin et al., 2009).

However, there is a gap in the literature that connects the phenomenological approach with a structured qualitative analysis of the experiences of student-teachers who have completed international practicums over the long term. This is a gap that the present authors seek to fill. We have used phenomenology to examine these experiences with participants who were also part of an earlier study immediately following their international practicum.

\section{Methodology}

We have selected a phenomenological research approach for this study. Phenomenology gives primacy to the richness and meaning of individual human experience. According to Welman and Kruger (1999, p. 189) "phenomenologists are concerned with understanding social and psychological phenomena from the perspectives of people involved". Phenomenology allowed us to move from the participants' responses to interview questions to examine the intentionally of their choices, describe them in detail, and reduce them to themes to examine their essence (Alexandersson, 1981). This approach allowed us to examine semi-structured reflections to uncover their essential structure.

To this end, two participants whose present contact information was available to researchers were contacted and agreed to participate in follow-up research. A semi-structured interview questionnaire was used to investigate the longevity of impact of the experience of teaching in rural Kenya with these two participants. Consistent with phenomenological methodology, only data that was from participants who lived the experiences was considered (Ray, 1985; Van Manen, 1984, 1997). This approach would allow researchers to examine responses that emerged from the participants' own frame of reference (Baker, Wuest, \& Stern, 1992) and identify aspects of the participants' dialectic relationship between self and his/her world.

Participants were contacted online through emails they had provided for previous research. Once they agreed to participate in this study, they signed letters of informed consent then participated in a semi-structured interview. Responses to prompts were written. This method was chosen for the interviews because of distance issues. One participant was teaching in England and one was working several hundred miles away from the research site so written responses allowed ease of access to both participants. Written responses also allowed researchers to examine responses separately, then collectively and re-examine them as themes emerged in the coding process (Creswell, 2002).

\section{Data Sources/Objects}

Phenomenology can be an unstructured approach to research because it reflects the nature of what is being studied. To provide the structure we felt was necessary to make meaning of the two interviews that provided the data for this study, we have used three qualitative approaches. First, we have used the categories of the framework we developed in the earlier research of this topic four years ago. These categories include: curriculum views, world views, and personal empowerment. Next, we examined the interview data to determine if there were qualitative changes in any of these aspects of personal transformation since the last contact with these 
teachers. This approach allowed us to access the qualitative method of comparison. In this case, we compared the qualities of comments made four years ago with those made in the current interviews. The third approach that was incorporated in this study was the use of case study analysis. Each participant's interview was examined to determine if further themes were evident that were attributable to the experiences in Kenya. The combined use of these three structures and a phenomenological perspective allowed us to examine many aspects of the data to determine meaning.

Interviews were semi-structured with the following questions:

\subsection{Demographics}

1) How old are you?

2) Are you currently working as a teacher?

3) If you answered, "yes" for number 2, identify the year that you started teaching.

4) If you answered "yes' for number 2, identify the location of your teaching job.

Country School Board

5) If you are not teaching at the moment, identify as many reasons why that is the case as apply to you.

6) If you have taught between graduation in June 2009 and the present, but are no longer teaching, explain why.

\subsection{Perception of Impacts}

7) Please comment on the long term impacts you perceive that you attribute to your experience in Kenya under the following sub-titles:

- your attitude toward global issues, including:

a) your commitment to basic human rights

b) your values related to cultural diversity and intercultural understanding

- your involvement with global issues

- your attitude toward resource sustainability, including:

a) your commitment to planetary sustainability

b) your view of the world as an interdependent system

- your involvement with resource sustainability initiatives (singularly or in organizations)

- your attitude toward social justice issues

a) in Canada

b) in other areas of the world

- your involvement in social justice issues

a) in Canada

b) in other areas of the world

c) factors that influence your level of involvement with social justice issues

- your instructional practice (if you are currently teaching), as sub-divided below:

- your commitment to child-centered pedagogy

- your sense of awareness of the individual differences in children

- your curriculum choices

- your use of teaching strategies that celebrate children's uniqueness

- your employment history (since fall 2009)

- your sense of satisfaction with your current job

- your sense of personal empowerment and belief in the power of individuals to make a positive difference

Please use this space to add any comments that relate to your perceptions of the long-term impacts of your experience in Kenya in 2009 as these relate to: 
a) personal impacts/ practices b) professional impacts/ practices

\subsection{Analysis of Data}

Respondents to the questionnaire were identified as Respondent A and Respondent B.

Respondent A is a 24-year-old male who graduated from the Concurrent Bachelor of Education program and was able to secure a position as an elementary school teacher in the United Kingdom. Respondent B is a 29-year-old female who graduated from a Consecutive Bachelor of Education Program and continued to pursue her career as an environmental educator in a non-school setting involved in the promotion of environmental sustainability.

\subsubsection{Categories of the Framework: Curriculum Views, Worldviews, and Personal Empowerment}

Responses to the questionnaire from both interviewees were compiled under the headings of the previous study's framework, which include curriculum views, world views and personal empowerment.

\subsubsection{Curriculum Views}

In this category, respondents were asked questions on how their experience in Kenya would still affect their commitment to child-centered pedagogy, their awareness of individual differences in children, their curriculum choices and the teaching strategies that celebrate children's uniqueness. Respondent A spoke of the importance of being fair and open to students' background and needs as well as treating them with respect and dignity:

I consciously meet with pupils...to find out more about their individual stories. I learnt this from the eagerness of students in Kenya to talk to you and tell you about them. If they think you genuinely don't care about them, they won't engage.

The influence of the experience seemed evident in the incorporation of the stories and experiences into the choice of curriculum and teaching strategies.

I design units and lessons based on things I have learnt in Kenya, such as sustainability. I believe in being flexible with teaching strategies, using Kenya photographs and stories as case studies for Citizenship Education and Geography development topics.

He also speaks of the importance of differentiated instruction in his lessons, as well as alternative resources. He tries to make projects open-ended to allow students to demonstrate their creativity and show their knowledge/understanding and talents in different ways.

Although Respondent B is not working as a teacher, her work as an environmental educator allows her to present education materials on the importance of environmental sustainability to school audiences who come to visit the environmental education center. She speaks of special projects in which she is involved. In particular, she states: "I teach about resource sustainability to students. I actively take part in initiatives such as removal of invasive species, planting trees, and planting indigenous species."

\subsubsection{World Views}

In this category the respondents were asked questions with regard to their commitment to planetary and resource sustainability, their views of the world as an independent system, their commitment to basic human rights, how they value cultural diversity and intercultural understanding as well as their views on global issues. Respondent A demonstrates a continued commitment to planetary and resource sustainability in his involvement in recycling projects both at home and at school. He speaks of using public transportation, carpooling and walking to school. "I try to teach with natural light and I am very conscious of not wasting energy, particularly leaving lights on, taps running, or wasting food". He is also committed to raising money for a children's charity, which provides equipment and opportunities for children to be involved in sports and play. He speaks of "...being very conscious of small daily decisions that are made, using my Kenya story to teach others". He states that he is eager to learn more of the language of Kenya, Swahili, to enable him access to more of the Kenyan culture. "The experience in Kenya has provided me with a greater understanding of what it is like to live in a third world country and depending on aid to survive".

Through her job as an environmental educator, respondent B speaks to several groups of all ages on the importance of sustainability and environmental protection. She is "...committed and determined to change the path of ecological destruction". She describes her own personal commitment to reduce waste by composting, reducing, reusing, and buying from local farmers. In terms of viewing the world as an independent system, she states that whether it is the Canadian Rockies or the Maasai Mara in Kenya there is interdependence between living and non-living organisms coexisting and depending on each other. 
Humans are interdependent with their environment and with each other. This is something very beautiful to witness, especially when it comes to family dynamics and ability to survive when you have a strong connected family. In Kenya, I witnessed this to be the glue that holds everyone and everything together.

She claims that she is an advocate for human rights on a daily/weekly basis and that social interaction and human rights are her passions. Every year since Kenya, she and her family now generously donate to the non-profit organization with whom she traveled to Kenya. This is a commitment that they honour towards the NGOs charitable work. She speaks of the importance of understanding other peoples' culture before making an assumption about the way they live. She values the time spent with people from another culture, another country.

\subsubsection{Personal Empowerment and the Ability to Make a Difference}

Respondent A indicated that, "...the decision to go to Kenya was the best I have made in my life; it truly was a life changing experience that was worth the time, money, and effort". He is eager to go on similar trips but feels that travelling in a group was the main reason why it was such a success. It feels that the trip was well organized and had an amazing group of people who all bonded together, adding to its overall impact.

Respondent B indicated:

One person can make a difference. I witnessed how the dream of one can change the lives of many when visiting Kenya. Becoming inspired is the easy part. Keeping inspired is the hard part. If you make it part of who you are, that is when it becomes easier with time. When individuals come together they form a group that makes a bigger impact. The impact can be big or small is doesn't matter. What matters is whether or not you are committed and if you have a sense of empowerment. Opportunities to travel and work with this $N G O$ empowered me to want to make a difference.

4.4 Qualitative Changes in Any of These Aspects of Personal Transformation since the Last Contact with These Teachers

The interviewees were asked to comment on their perceptions of the long-term impacts of their experience in Kenya as they relate to their personal empowerment and professional practice. Respondent A reflects:

Teaching in Kenya helped me "grow up" as a teacher much quicker and see how important basic education is to children. I grew in confidence seeing that the children wanted to learn and were desperate for attention. This helped me change the way I teach so that I try and really connect with students rather than just transferring information to them. I try to make the learning as "real" and useful as possible to the students by using photographs, models, and STORIES to demonstrate importance of knowledge and skills.

Respondent B indicates that:

I will not forget how much happiness I felt when I was spending time with the children and adults in Kenya. I did not feel sad for their poverty. I felt joy and happiness from all the songs and stories we shared. When I was in Kenya I became inspired. My inspiration comes from the children and the land. When I share a story to others about Kenya, I only share the happy times and fun we had. They don't want anyone feeling sorry for them. They want others to feel their joy and a commitment to their home place. My students will always, every day be encouraged to be the change they wish to see in the world. I will inspire my students through education about how they can make a difference.

Responses retrieved from the two interviewees four months after the return from Kenya and the responses retrieved four years later were also compared. The responses in the initial survey around the same topics of the organizational framework were more emotive in nature whereby the more recent responses seemed to demonstrate residual impact in shaping them as individuals. It is remarkable to note how their convictions have remained the same and how they are attempting to follow through with what they set out to accomplish.

Respondent $\mathrm{A}$ in the first study stated that:

Whether I've left a light on or spilled some water, I always think of those smiling young faces at Enelorai who were so happy yet lived on so little. Personally I know that my trip to Kenya was only the beginning of a lifelong journey...I now aim to bring awareness of these issues to those who have not seen it for themselves. I bring my photographs, my bracelets, my stories, and a big smile with me wherever I go and it is amazing how many people will stop and listen.

Four years later, he speaks of this experience with sincerity and conviction. He has internalized and assimilated this experience and has kept his promise to tell others through the use of his artifacts as testimonies of his convictions. 
I think about Enelerai very frequently, and constantly refer to my photographs and stories when speaking with friends, and in the classroom with students. It was truly a special experience that I feel privileged to have been part of.

In the initial interview, Respondent B also demonstrates consistency with her earlier statements about her convictions. Four years ago she spoke of how the experience in Kenya opened her eyes to the reality of the situation and how there is a need to convey a message that has more meaning, emotion, and compassion.

Going to Kenya and working with [the NGO] has become something that I will never forget and hopefully I will continue to work with them. As teachers we have the power to influence others and to continue to work in direct ways with the organization. I cannot wait until the day I again embark on a Kenyan adventure and share it with young minds and instill the passion in them that was instilled in me.

Today, she speaks of how she continuously supports the work of the NGO by becoming involved in many of their initiatives. She has also internalized and assimilated this experience:

After going to Kenya, I became involved with the NGO. I have certainly not done enough with this organization that I am so passionate about. I know my journey and work with them is by no means complete; it's just begun. Kenya inspired me to become excited about the work that gets done by many selfless people all over the world and the difference that even one person can make.

\subsection{Case Study Analysis}

Upon examining the data, there were interesting elements that were evident that were not part of the original framework but were obvious in respondents' reflections in this study. In this second study, it was evident that participants were more aware of how this experience had transformed their view of social justice. Interestingly, both respondents identified the transferability of the issues of inequities in Kenya with those seen in their respective communities or countries, Canada or abroad. Respondent A was concerned about the growing gap in social/economic hierarchy in Canada and the United Kingdom.

Respondent B made an analogy between the social issues of the people in Kenya and those of the First Nations people in Canada.

My passion here in Canada is with the Aboriginal People. I strongly disagree with what is happening on First Nations' reserves in regards to their water quality, basic standard of living and education for their children. I am horrified that this is taking place here in our own country when I have seen so much of this in Kenya. Students are not learning enough about social justice issues in schools. Therefore, they have no sense of power to help make change take place within their own community.

It is evident from the data in the second study that the Kenyan experience had a long-term impact on the two respondents. It appears that these participants each related strong emotive responses immediately after their experience in Kenya. Four years later, these strong emotions continue to be evident but are now also enriched by a set of professional beliefs that guide and inform their daily professional practice and form a basis for decisions in their personal lives.

\section{Conclusions}

The responses of each of these participants indicate that they each, in different ways, attribute aspects of their current lifestyles and career choices and practices to experiences they had in Kenya. Even four years after this experience, each participant describes the experiences as vividly remembered and synthesized. The participants have not only retained the initial impact of the experience that they described as differences in the curriculum views, world views, and sense of personal empowerment, but, time has distilled their reflections into strongly held beliefs about themselves as professionals, and about their relationship to those whom they teach and to fellow citizens of the world. Their sense of respect for other people of vastly different life circumstances is evident in the tone, substance, and examples they provided in their interviews. Comments such as, "I realize the importance there is to understand other peoples' culture before making an assumption about the way they live", testify to the strength and endurance of the participants' learning from the international practicum.

Time has provided further opportunity for learning in one context to be generalized to other contexts for each participant.

There was a time in Kenya that the pathway to understanding and relating opened up for me. I traveled to Kenya with a basic idea about how they would live and I left with an understanding, appreciation and connection to the way they live their life and their beliefs. I value the relationships that I can have with anyone, anywhere in the world now. I realize the importance there is to understand other peoples' culture 
before making an assumption about the way they live. I value time spent with people from another culture, another country. I want to learn more now and don't feel so shy about asking questions.

The participants' sense of confidence that new understandings evolved through new experiences and that they needed to seek to understand and work on making meaning of their experiences was very different from the reflections on this experience immediately following the return trip from Kenya. There was a deeper sense from each participant that learning to know about the "others" is fairly easy, but learning to understand and appreciate them is a growth process that ripens as they gain perspective on initial experiences. This finding is critical to the contribution of this study to the body of knowledge about the impacts of international teaching practica experiences in developing countries.

It was interesting to note that both participants identified that they continue to use their stories about living and working in Kenya in their current teaching roles as a way to help those they teach understand social issues such as compassion, tolerance, and social justice. Similarly, both participants continue their involvement with the NGO that hosted their work in Kenya. One participant saw this as a way to keep herself and her extended family engaged in global change issues and initiatives. It may be that we can further strengthen this experience by incorporating post-experience opportunities to share stories and discuss their impacts and implications as part of the re-entry process after this practicum.

\section{Discussion}

International practica experiences are an expensive and time-consuming alternative for pre-service teachers. Not all pre-service programs in teacher preparation provide the option of an alternative international practicum within their program structure. This limitation reflects the cost of such an option to the pre-service teacher but also responds to the reality of limitations on time in pre-service programs to engage in the required number of weeks or hours of traditional classroom placement. Additionally, arrangements to live and work in some international contexts are both difficult to make and embedded in inherently risky and unstable political contexts. It is little wonder, given these obstacles, that such international practica experiences are not commonly available to all pre-service teachers.

However, what this study has shown so strongly is the enduring value of such an experience. It is clear that the emotive reflections of participants shortly after an international practica were enriched by more mature and philosophical beliefs and committed professional practices over time. As one participant so profoundly stated, "Becoming inspired is the easy part. Keeping inspired is the hard part". These participants both recognized that what they do with their own students to create awareness of their individual power to make a difference to others is a critical part of their professional commitment to the types of teachers they want to be. They each felt that experiencing Kenya made them more aware of social issues and moved their knowledge toward understanding. Since addressing social issues in a critical way is so much a part of teachers' roles, an international practicum such as this Kenya experience may have the potential to provide significant and unique contributions to a teacher's ability to teach about such issues in classroom contexts. Further research into the strategies and beliefs of teachers who have had the opportunity for this form and practica compared to those who have not is needed.

We are entering an era of review of teacher preparation programs in the Canadian context. These reviews are in response to government mandates to standardize requirements across the country and address teacher mobility. As we review teacher preparation programs, we should consider the value of international practica as a site of opportunity to engage pre-service teachers. International practica in developing countries can help pre-service teachers internalize key curricular concepts about culture, multi-culturalism, pluralism, and multi-racism, while supporting their life-long commitment to understanding themselves as global influences on children. If every pre-service teacher had a program-embedded opportunity to participate in this type of international practica, we could anticipate a growing impact on their stature as teachers with enriched curriculum views, widened world views, and contagious senses of personal empowerment.

Phenomenology examines the lived experience of research participants and values the lessons learned from personal experiences. By examining reflections about the lived experience of our participants, we were able to identify the existence and nature of the long-term resonance that was created by the experience. Issues and values that came to the foreground immediately after the experience in Kenya continue to be evident in these two teachers and the actions they take in their professional lives show that these issues and values are deeply embedded in their professional "self".

While this research offers hope and encouragement about the promising impact of strongly emotive growth opportunities during professional practicum parts of a teacher preparation program, further work needs to be done. Examination of the practices and expressed values of early career teachers who have had an international 
practica with their peers whose practica lacked the international component in a developing country would provide insight into the extent that we can be confident that this professional growth is attributable to the uniqueness of the experience. If we can confidently say that we are achieving key differences in curriculum views, world views, and personal practices in those who experience developing world international practica, but not achieving these outcomes where the international aspect of a professional preparation program are not present, then we will have solid data on which to base decisions that will require a significant investment in time and money. We would have a basis to consider the question: Can we enrich the practicum and enrich the world?

\section{References}

Alexandersson, C. (1981). Amedeo Giorgis Empirical Phenomenology. Göteborg, Sweden: University of Göteborg.

Armstrong, P. D. (2009). New Beginnings: A Phenomenology of the Lived Experiences of Novice Secondary Teachers Who Have Completed the Induction and Mentorship Requirements of Utah's Early Years Enhancement (Eye) Program. Utah State University.

Baker, C., Wuest, J., \& Stern, P. N. (1992). Method slurring: the grounded theory/phenomenology example. Journal of Advanced Nursing, 17(11), 1355-1360. http://dx.doi.org/10.1111/j.1365-2648.1992.tb01859.x

Baxter, J. (2012). The long-term impact of a 1-month international teaching practicum on preservice teachers. (M.Ed. Unpublished master's dissertation), Nipissing University, North Bay, Canada.

Bernard, R. (2005). Making Music, Making Selves: A Call for Reframing Music Teacher Education. Action, Criticism, and Theory for Music Education, 4(2).

Betts, R. T. (2006). Lived experiences of long-term supply beginning teachers in New Brunswick: A hermeneutic phenomenological approach. University of New Brunswick (Canada).

Bowen, M., Roth, W. M., Gupta, A., Sefton, T., Stanley, D., Dalton, J., ... Zimmerman, P. (2002). Student Teachers' Perceptions of their Paired Practicum Placement Experiences. Journal of Teaching and Learning, $2(1), 2$.

Brindley, R., Quinn, S., \& Morton, M. L. (2009). Consonance and dissonance in a study abroad program as a catalyst for professional development of pre-service teachers. Teaching and Teacher Education, 25(3), 525-532. http://dx.doi.org/10.1016/j.tate.2008.09.012

Cohen, M. Z., Kahn, D. L., \& Steeves, R. H. (2000). Hermeneutic Phenomenological Research: A Practical Guide for Nurse Researchers. SAGE Publications.

Creswell, J. W. (2002). Education Research: Planning, Conducting, and Evaluating Quantitative and Qualitative Research. Upper Saddle River, NJ: Merrill Prentice Hall.

Dall'Alba, G. (2010). Exploring Education Through Phenomenology: Diverse Approaches. John Wiley \& Sons. http://dx.doi.org/10.1002/9781444322828

Ferguson, M. R. (2011). Finding a Home Abroad With "Eveline": Using Narrative Inquiry to Establish a Sense of Place for a Western Teacher in a Foreign and Multicultural Context. Journal of Studies in International Education, 15(1), 25-40. http://dx.doi.org/10.1177/1028315309337928

Firmin, M. W., Firmin, R. L., \& MacKay, B. B. (2009). Spiritual Dynamics Involved with Overseas Student Teaching: A Qualitative Analysis. Christian Higher Education, 8(2), 132-155. http://dx.doi.org/10.1080/15363750802623156

Giles, D. L. (2008). Exploring the teacher-student relationship in teacher education: A hermeneutic phenomenological inquiry. (PhD Unpublished doctoral thesis), Auckland University of Technology, Auckland, New Zealand.

Grushka, K., McLeod, J. H., \& Reynolds, R. (2005). Reflecting upon reflection: Theory and practice in one Australian university teacher education program. Reflective Practice, 6(2), 239-246. http://dx.doi.org/10.1080/14623940500106187

Guo, Y., Arthur, N., \& Lund, D. (2009). Intercultural inquiry with pre-service teachers. Intercultural Education, 20(6), 565-577. http://dx.doi.org/10.1080/14675980903448619

Husserl, E. (1970). Crisis of European sciences and transcendental phenomenology. Northwestern University Press. 
Kennedy, K. M. (2010). The Essence of the Virtual School Practicum: A Phenomenological Study of Pre-service Teachers' Experiences in a Virtual School. (PhD Unpublished doctoral thesis), University of Florida, Gainesville.

Larocco, M. J. F. (2011). International Teaching Assistants and the Essence of the Development of Intercultural Competence. University of Rhode Island and Rhode Island College.

Maynes, N., Allison, J., \& Julien-Schultz, L. (2012). International Practica Experiences as Events of Influence in a Teacher Candidates' Development. McGill Journal of Education, 47(1), 69-91. http://dx.doi.org/10.7202/1011667ar

McGaha, J. M., \& Linder, S. M. (2012). The Impact of Studying Abroad on Male Preservice Teachers: A Phenomenological Investigation. Multicultural Perspectives, 14(3), 163-168. http://dx.doi.org/10.1080/15210960.2012.697011

Melby, C. S., Dodgson, J. E., \& Tarrant, M. (2008). The Experiences of Western Expatriate Nursing Educators Teaching in Eastern Asia. Journal of Nursing Scholarship, 40(2), 176-183. http://dx.doi.org/10.1111/j.1547-5069.2008.00223.x

Moustakas, C. (1994). Phenomenological Research Methods. SAGE Publications.

Orndorff, E. B. (1999). The Short-term Travel Experience for Adult Professionals: A Phenomenological Study. Virginia Polytechnic Institute and State University.

Putney, M. W. (2011). The Phenomenology of Teacher Tenure in North Carolina: A Study of Teacher Tenure from the Perspective of Teachers. (Ed.D. unpublished doctoral thesis), North Carolina State University, United States -- North Carolina. ProQuest Dissertations \& Theses (PQDT) (UMI 3497211) database.

Rapoport, A. (2008). Exchange programs for educators: American and Russian perspectives. Intercultural Education, 19(1), 67-77. http://dx.doi.org/10.1080/14675980701852418

Ray, M. (1985). A philosophical method to study nursing phenomena. Qualitative research methods in nursing, 81-92.

Ross, P. G., \& Krider, D. S. (1992). Off the plane and into the classroom: A phenomenological explication of international teaching assistants' experiences in the American classroom. International Journal of Intercultural Relations, 16(3), 277-293. http://dx.doi.org/10.1016/0147-1767(92)90053-W

Swisher, L. N. (2011). Examining practicing teachers' understandings of mentoring and the student teaching field experience. (Ed.D. 3475837), University of Pennsylvania, United States -- Pennsylvania. Retrieved from http://repository.upenn.edu/dissertations/AA13475837/

Van Benschoten, M. J., \& Albany, S. U. O. N. Y. A. (2008). A Phenomenological Case Study of Teacher Collaboration: Teachers' Narratives of "what It's Like" for Them. State University of New York at Albany.

Van Eekelen, I., Vermunt, J., \& Boshuizen, H. (2006). Exploring teachers' will to learn. Teaching and teacher education, 22(4), 408-423. http://dx.doi.org/10.1016/j.tate.2005.12.001

Van Manen, M. (1984). Practicing phenomenological writing. UALibraries Site Administrator Test Journal, 2(1), 36-69.

Van Manen, M. (1990). Researching Lived Experience: Human Science for an Action Sensitive Pedagogy: State University of New York Press.

Van Manen, M. (1995). On the epistemology of reflective practice. Teachers and Teaching: Theory and practice, l(1), 33-50. http://dx.doi.org/10.1080/1354060950010104

Van Manen, M. (1997). Phenomenological pedagogy and the question of meaning. In D. Vandenberg (Ed.), Phenomenology \& education discourse (pp. 41-68). Johannesburg: Heinemann.

Van Manen, M. (2008). Pedagogical Sensitivity and Teachers Practical Knowing-in-Action. Peking University Education Review, 1, 1-23. 